\title{
Cucurbitacin B inhibits proliferation and induces apoptosis via STAT3 pathway inhibition in A549 lung cancer cells
}

\author{
MENG ZHANG $^{1}$, ZHI-GANG BIAN ${ }^{2}$, YI ZHANG ${ }^{1}$, JIA-HE WANG ${ }^{1}$, \\ LIANG KAN $^{1}$, XIN WANG ${ }^{1}$, HUI-YAN NIU ${ }^{1}$ and PING HE ${ }^{1}$ \\ Departments of ${ }^{1}$ Geriatrics and ${ }^{2}$ Otolaryngology, Shengjing Hospital of China Medical University, \\ Shenyang, Liaoning 110004, P.R. China
}

Received December 2, 2013; Accepted July 21, 2014

DOI: $10.3892 / \mathrm{mmr} .2014 .2581$

\begin{abstract}
Natural products are a great source of cancer chemotherapeutic agents. The present study was conducted to investigate whether cucurbitacin $\mathrm{B}(\mathrm{CuB})$, one of the most potent and widely used cucurbitacins, inhibits proliferation and induces apoptosis in the A549 lung cancer cell line. Furthermore, $\mathrm{CuB}$ induced apoptosis of A549 cells in a concentration-dependent manner, as determined by fluorescence microscopy, flow cytometry and transmission electron microscopy. The present study also demonstrated that $\mathrm{CuB}$ dose-dependently inhibited lung cancer cell proliferation, with cell cycle inhibition and cyclin B1 downregulation. Apoptosis induced by $\mathrm{CuB}$ was shown to be associated with cytochrome $c$ release, B-cell lymphoma 2 downregulation and signal transducer and activator of transcription 3 pathway inhibition. $\mathrm{CuB}$ may prove to be a useful approach for the chemotherapy of lung cancer.
\end{abstract}

\section{Introduction}

Lung cancer is one of the most common malignant tumor types worldwide, with increasing incidence and mortality rates (1). Despite the development of improved therapy modalities in the past two decades, the five-year survival rate has remained $<15 \%$ (2). Several studies have suggested that conventional therapies may have reached a therapeutic plateau. Therefore, the current challenge is to investigate new therapeutic agents to treat lung cancer and other malignancies.

Previously, there has been growing interest in the use of natural products as a new source of anticancer drugs $(3,4)$. Cucurbitacins are compounds originally isolated from Cucurbitaceae plants (5). They are a group of diverse

Correspondence to: Dr Ping He, Department of Geriatrics, Shengjing Hospital of China Medical University, 36 Sanhao Road, Shenyang, Liaoning 110004, P.R. China

E-mail: zhangm@sj-hospital.org

Key words: A549 lung cancer cell line, cucurbitacin B, apoptosis, STAT3 triterpenoid molecules with a number of biological properties, including cytotoxic, antitumor, hepatoprotective, anti-inflammatory, antimicrobial, antihelminthic and cardiovascular activities (6,7). Cucurbitacin B (CuB) (Fig. 1) is one of the most potent and widely used cucurbitacins (5). Accumulated evidence demonstrated that $\mathrm{CuB}$ induces apoptosis and inhibits the growth of various human cancer cell lines $(5,7,8)$.

It was reported that numerous components of herbal medicine may induce apoptosis in lung cancer cells through the mitochondrial pathway $(9,10)$. In another study, CuB treatment increased the protein levels of caspase- 9 in the pancreatic cancer cell line Panc-1 (11). However, whether $\mathrm{CuB}$ is able to cause apoptosis of lung cancer cells in a mitochondria-dependent manner remains elusive.

In the present study, the anticancer effect of $\mathrm{CuB}$ on A549 lung cancer cells was investigated. The effect of $\mathrm{CuB}$ on cell proliferation, cell cycle distribution, apoptosis, caspase activity and cytochrome $c$ release was examined. In addition, the possible mechanisms underlying this effect were investigated by screening a panel of proteins relevant to cell proliferation and apoptosis pathways.

\section{Materials and methods}

Reagents and chemicals. Highly purified $\mathrm{CuB}$ was purchased from the National Institute for the Control of Pharmaceutical and Biological Products (Beijing, China). RPMI-1640 and trypsin were purchased from Biological Industries (Kibutz Beit Haemek, Israel). Fetal bovine serum (FBS) and 3-(N-Morpholino)propanesulfonic acid (MOPS) buffer were purchased from Solarbio (Beijing Solarbio Science \& Technology, Beijing, China). MTT, dimethyl sulfoxide (DMSO), propidium iodide (PI), Hoechst 33258 and rhodamine 123 were purchased from Sigma-Aldrich (St. Louis, MO, USA). Annexin V-fluorescein isothiocyanate (FITC) Apoptosis kit and bicinchoninic acid (BCA) protein assay kit were purchased from Key Gene (Nanjing, China). Mouse monoclonal antibodies specific to phosphorylated and total signal transducer and activator of transcription 3 (STAT3), cytochrome $c$, B-cell lymphoma 2 (Bcl-2), cyclin B1 and $\beta$-actin and the horseradish peroxidase (HRP) conjugated goat anti mouse immunoglobulin (Ig) G secondary antibody were purchased from Santa Cruz Biotechnology, Inc., (Santa 
Cruz, CA, USA). Enchanced Chemoluminescence Plus (ECL Plus) kit was purchased from Thermo Fisher Scientific, Inc., (Thermo Scientific Pierce, Waltham, MA, USA). All other chemicals were obtained from Sinopharm Chemical Reagent Shenyang Co., Ltd. (Shenyang, China).

Cell culture. The human lung cancer cell line A549 was obtained from the China Center for Type Culture Collection (Wuhan, China). The cells were cultured in RPMI-1640 containing $10 \%$ fetal calf serum at $37^{\circ} \mathrm{C}$ in $5 \% \mathrm{CO}_{2}$. The culture medium was replaced every day. The cells for the assays were detached using a solution of $0.25 \%$ trypsin and $0.02 \%$ EDTA.

Cell viability assay. Viability was assessed by the MTT assay. Approximately $5 \times 10^{3}$ cells were plated per well in 96-well plates and treated with different concentrations of $\mathrm{CuB}(0.02$, $0.1,0.5,2.5,12.5$ and $62.5 \mu \mathrm{mol} / \mathrm{l})$ for 24,48 and $72 \mathrm{~h}$, respectively. Corresponding DMSO and culture medium were used either as a control or empty control. For quantitation of cell viability, $25 \mu 1$ MTT solution [ $(2 \mathrm{mg} / \mathrm{ml}$ in phosphate-buffered saline (PBS)] was added to each well, and the plates were incubated for an additional $4 \mathrm{~h}$ at $37^{\circ} \mathrm{C}$. The medium was then removed and $150 \mu \mathrm{l}$ DMSO was added to each well to solubilize the formazan crystals formed in viable cells. Each solution was measured spectrophotometrically at $570 \mathrm{~nm}$ (OD570) using an ELISA plate reader (Model 550; Bio-Rad, Hercules, CA, USA). At least three independent experiments were performed.

Flow cytometry for cell cycle analysis. The cells were seeded into six-well plates at a concentration of $5 \times 10^{5} /$ well and allowed to attach in culture overnight, then treated with either 0.1 or $1 \mu \mathrm{mol} / 1 \mathrm{CuB}$ for $24 \mathrm{~h}$ and harvested. For cell cycle analysis, the cells were fixed in $70 \%$ ice cold ethanol at $4^{\circ} \mathrm{C}$ overnight. The cells were then washed with PBS, treated with RNase and stained with PI $(100 \mu \mathrm{g} / \mathrm{ml})$ in the dark for $30 \mathrm{~min}$ at room temperature. The samples were analyzed by a FACScan flow cytometer (BD Biosciences, Franklin Lakes, NJ, USA). At least three independent experiments were performed.

Flow cytometric analysis of apoptosis. For Annexin V/PI apoptosis analysis, $5 \times 10^{5}$ cells were plated per well in six-well plates and treated with either 0.1 or $1 \mu \mathrm{mol} / 1 \mathrm{CuB}$ for $24 \mathrm{~h}$. Following harvesting, the cells were resuspended in cold PBS and stained using an Annexin V-FITC Apoptosis kit according to the manufacturer's instructions. The cells were analyzed using a FACScan flow cytometer. At least three independent experiments were performed.

Fluorescence microscopy. The cells $\left(5 \times 10^{5}\right)$ were grown on coverslips placed into six-well plates. Following treatment with different concentrations of $\mathrm{CuB}(0.1 \mu \mathrm{mol} / 1,1 \mu \mathrm{mol} / \mathrm{l})$ or an equal concentration of DMSO for $24 \mathrm{~h}$, the cells were washed twice with cold PBS, fixed with cold methanol and acetic acid $(3 / 1, v / v)$ at $4^{\circ} \mathrm{C}$ overnight and stained with Hoechst 33258 for $30 \mathrm{~min}$ in the dark, washed again in PBS and finally mounted in mounting medium (80\% glycerol in PBS). Morphological changes were analyzed under an E800 fluorescence microscope (Nikon, Tokyo, Japan).

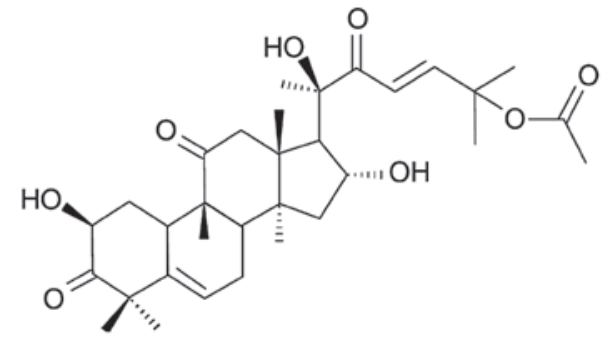

Figure 1. Chemical structure of cucurbitacin B.

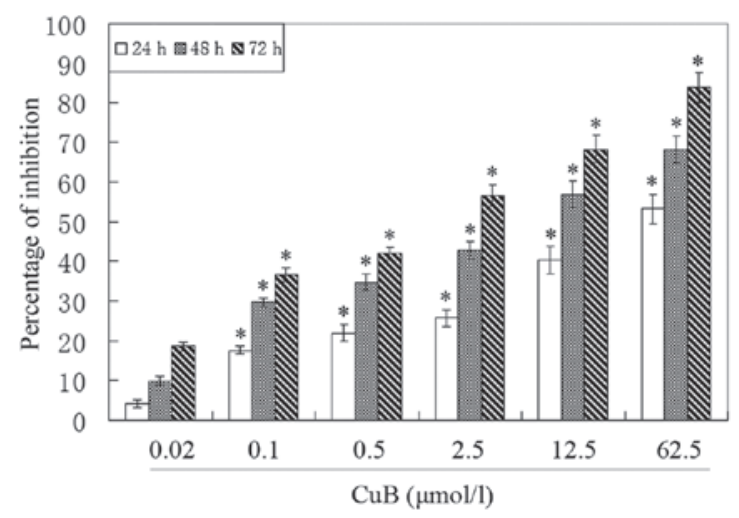

Figure 2. The proliferative inhibition effects of $\mathrm{CuB}$ on human lung cancer A549 cells. ${ }^{*} \mathrm{P}<0.05$ vs. the control group. $\mathrm{CuB}$, cucurbitacin $\mathrm{B}$.

Transmission electron microscopy. The cells treated with $1 \mu \mathrm{mol} / \mathrm{l} \mathrm{CuB}$ for $24 \mathrm{~h}$ were harvested and fixed with $3 \%$ glutaraldehyde overnight. Following removal of the primary fixative, the cells were washed three times with MOPS buffer, post-fixed in $1 \%$ osmium tetroxide $\left(\mathrm{OsO}_{4}\right)$, dehydrated in an ethanol series and embedded in epoxy resin. Ultra-thin sections were double-stained with lead citrate/uranyl acetate prior to examination using a JEM-100CX transmission electron microscope (Japan Electron Optics Laboratory Co., Ltd, Tokyo, Japan).

Caspase-3 and caspase-9 activity assay. The activity of caspase- 3 and caspase- 9 was detected by chromogenic substrate assay. The cells were seeded in $75 \mathrm{~cm}^{2}$-culture flasks and cultured for $24 \mathrm{~h}$. The cells were then treated with $1 \mu \mathrm{mol} / \mathrm{CuB}$ for $24 \mathrm{~h}$ and harvested. An equal volume of culture medium was added to the control group. The protein was then extracted with lysis buffer and quantified with a BCA protein assay kit. A total of $200 \mu \mathrm{g}$ protein was prepared, diluted to a volume of $50 \mu \mathrm{l}$, $50 \mu 1$ of $2 \mathrm{X}$ reaction buffer was added with $5 \mu \mathrm{l}$ substrate of caspase- 3 or caspase- 9 . A total of $50 \mu 1$ lysis buffer and $50 \mu 12 \mathrm{X}$ reaction buffer was added to the control group. Following incubation for $4 \mathrm{~h}$ at $37^{\circ} \mathrm{C}$, the absorbance was measured at $405 \mathrm{~nm}$. At least three independent experiments were performed.

Detection of the mitochondrial membrane potential $(\Delta \psi m)$. The A549 cells (5x105/well) were seeded into six-well plates and then treated with $0.1 \mu \mathrm{mol} / 1$ or $1 \mu \mathrm{mol} / 1 \mathrm{CuB}$ for $24 \mathrm{~h}$. An equal amount of culture medium was added as the control. The cells were harvested and incubated with $10 \mathrm{mg} / \mathrm{ml}$ rhodamine 123 for $30 \mathrm{~min}$ at $37^{\circ} \mathrm{C}$. The cells were resuspended with PBS and analyzed using a FACScan flow cytometer. At least three independent experiments were performed. 
A

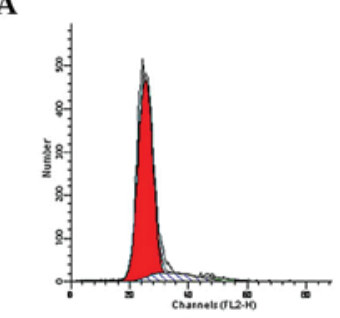

B

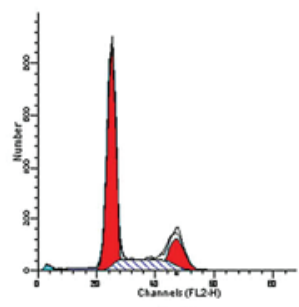

0.1

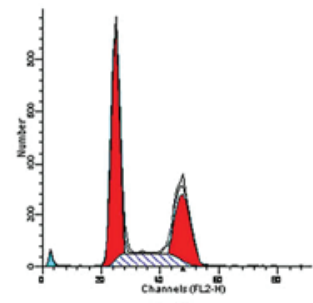

1.0

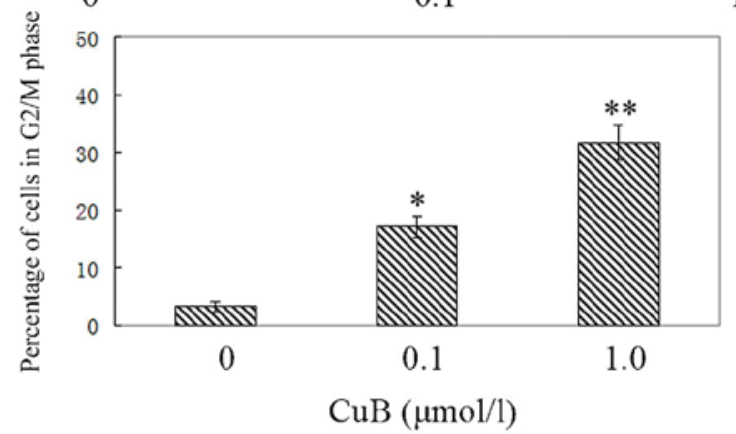

Figure 3. Flow cytometric cell cycle analysis. (A) A549 cells were treated with $\mathrm{CuB}(0,0.1$ and $1.0 \mu \mathrm{mol} / \mathrm{l})$ for $24 \mathrm{~h}$. The cells were then harvested and stained with propidium iodide. The cell cycle distribution was analyzed by flow cytometry. (B) Percentage of cells in G2/M phase in histograms. "P<0.05 vs. the control group; ${ }^{* *} \mathrm{P}<0.01$ vs. the control group. $\mathrm{CuB}$, cucurbitacin $\mathrm{B}$.

Western blot analysis. The cells were seeded in culture flasks and then incubated with $0.1 \mu \mathrm{mol} / 1$ or $1 \mu \mathrm{mol} / 1 \mathrm{CuB}$ for $24 \mathrm{~h}$. An equal amount of RPMI-1640 was added to the control group. Total extracted protein, cytoplasmic protein or mitochondrial protein were analyzed separately. The proteins were separated by SDS-PAGE and transferred to polyvinylidene fluoride membranes. The membranes were blocked with $5 \%$ non-fat milk and incubated overnight at $4^{\circ} \mathrm{C}$ with antibodies against phosphorylated and total STAT3, cytochrome $c, \mathrm{Bcl}-2$, cyclin B1 and $\beta$-actin $(1: 1,000)$. Following incubation with peroxidase-conjugated anti-mouse $\operatorname{IgG}(1: 10,000)$ at room temperature for $1 \mathrm{~h}$, the proteins were visualized using an ECL Plus kit and detected using a ChemiDoc-It BioImaging system (UVP Inc., Upland, CA, USA).

Statistical analysis. Values are expressed as the mean \pm standard deviation. The statistical correlation of data was examined for significance by analysis of variance and Student's t-test. $\mathrm{P}<0.05$ was considered to indicate a statistically significant difference. These analyses were performed using SPSS 13.0 software (SPSS, Inc., Chicago, IL, USA).

\section{Results}

CuB inhibits A549 cell proliferation. To evaluate the effect of $\mathrm{CuB}$ on the proliferation of A549 cells, an MTT assay was performed. It was observed that the growth of A549 cells was suppressed in a dose- and time-dependent manner (Fig. 2).

CuB induces $G 2 / M$ cell cycle arrest in A549 cells. To further investigate the inhibitory effect of $\mathrm{CuB}$ on cell growth, the cell cycle distribution in A549 cells was examined by flow cytometry. The cells in the experimental groups were treated with $0.1 \mu \mathrm{mol} / 1$ and $1 \mu \mathrm{mol} / 1 \mathrm{CuB}$. As shown in Fig. 3, when the dose of $\mathrm{CuB}$ was increased, the percentage of cells in the $\mathrm{G} 2 / \mathrm{M}$ phase increased markedly. In the control group, the percentage of cells in $\mathrm{G} 2 / \mathrm{M}$ phase was $3.26 \pm 1.02 \%$ and in the $\mathrm{CuB}$ high-dose group, the $\mathrm{G} 2 / \mathrm{M}$ percentage was $31.78 \pm 3.69 \%$. The results demonstrated that $\mathrm{CuB}$ induced $\mathrm{G} 2 / \mathrm{M}$ arrest significantly.

CuB induces apoptosis of A549 cells. AnnexinV/PI analysis was employed to examine the effect of $\mathrm{CuB}$ on apoptosis in A549 cells. It was identified that $\mathrm{CuB}$ induced apoptosis of A549 cells evidently. The percentages of early and late apoptotic cells were significantly increased compared with the control group. The proportion of apoptotic cells in the treated cells was increased in a dose-dependent manner (Fig. 4).

Following treatment with $\mathrm{CuB}$ for $24 \mathrm{~h}$, the A549 cells exhibited typical morphological hallmarks of apoptosis, including condensation of chromatin, karyopyknosis and nuclear fragmentation, which was observed using Hoechst 33258 staining (Fig. 5). As the dose of CuB increased, the rate of cell apoptosis increased.

Ultrastructural changes caused by $\mathrm{CuB}$ in A549 cells were also examined. Transmission electron microscopic analysis demonstrated morphological alterations in the A549 cells treated with $\mathrm{CuB}$. The cells treated with $1.0 \mu \mathrm{mol} / \mathrm{l} \mathrm{CuB}$ for $24 \mathrm{~h}$ lost their pseudopodia and exhibited evidence of cell shrinking, intracytoplasmic vacuoles, chromatin condensation and mitochondrial swelling (Fig. 6).

$C u B$ induces caspase-3 and -9 activation. To further investigate the effect of $\mathrm{CuB}$ on apoptosis, the activation of caspase-3 and caspase-9 in A549 cells was examined using caspase activity assay kits. The proteolytic activity of both caspase-3 and caspase-9 was significantly increased following treatment with $\mathrm{CuB}$ for $24 \mathrm{~h}$ (Fig. 7).

$C u B$ induces disruption of the $\Delta \psi m$ and cytochrome c release. The effect of $\mathrm{CuB}$ on $\Delta \psi \mathrm{m}$ following $\mathrm{CuB}$ treatment was 
A

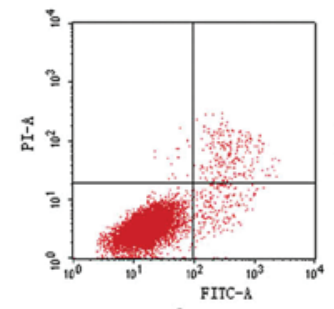

B

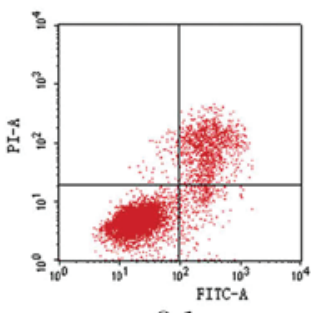

0.1

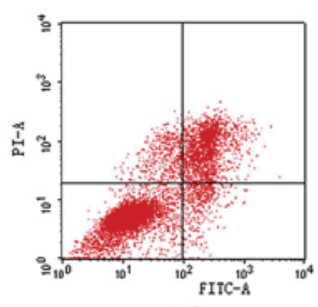

1.0

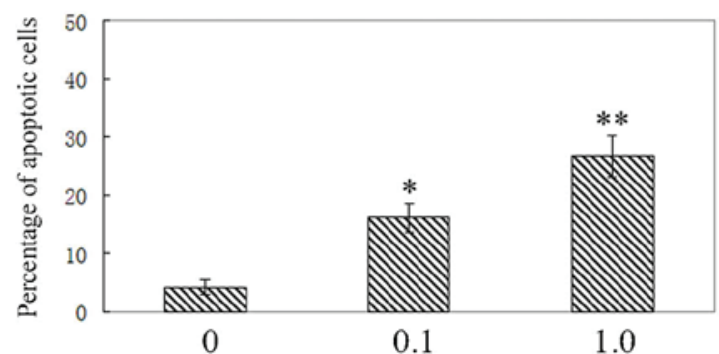

$\mathrm{CuB}(\mu \mathrm{mol} / 1)$

Figure 4. Flow cytometric quantification of apoptotic cells. (A) CuB-induced apoptosis in A549 cells as assayed by Annexin V/PI staining. A549 cells were treated with $\mathrm{CuB}(0,0.1$ and $1.0 \mu \mathrm{mol} / 1)$ for $24 \mathrm{~h}$. The cells were then harvested and stained with Annexin V/PI prior to flow cytometric analysis of apoptosis (B) Quantification of apoptotic cells from A in a bar chart. " $\mathrm{P}<0.05$ vs. the control group; ${ }^{* *} \mathrm{P}<0.01$ vs. the control group. CuB, cucurbitacin B; PI, propium iodide; FITC, fluorescein isothiocyanate.

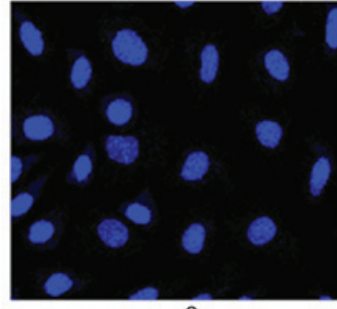

0

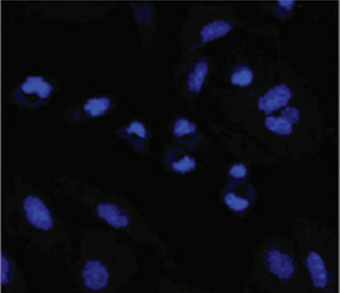

0.1

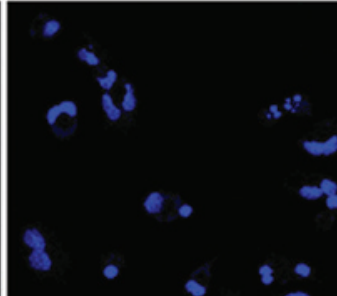

1.0

$\mathrm{CuB}(\mu \mathrm{mol} / \mathrm{l})$

Figure 5. Cell apoptosis observed by Hoechst 33258 staining. A549 cells treated with $\mathrm{CuB}(0,0.1$ and $1.0 \mu \mathrm{mol} / \mathrm{l})$ for $24 \mathrm{~h}$. Apoptotic cells exhibited chromatin condensation and nuclear fragmentation. CuB, cucurbitacin B. Magnification, x400.

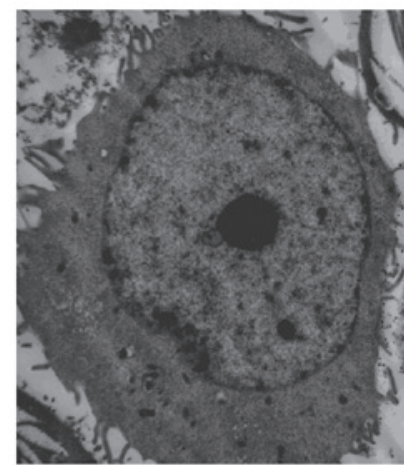

Control

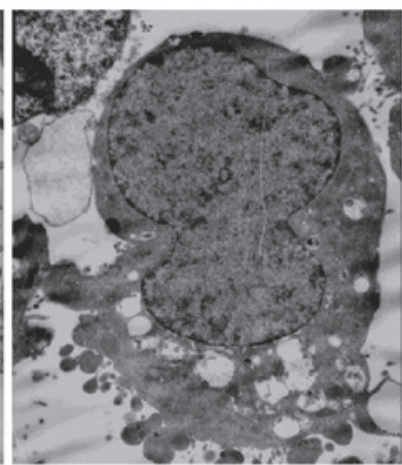

$\mathrm{CuB}(1.0 \mu \mathrm{mol} / \mathrm{l})$

Figure 6. Transmission electron micrographs of A549 control cells and cells treated with $\mathrm{CuB}(1.0 \mu \mathrm{mol} / \mathrm{l})$ for $24 \mathrm{~h}$. The treated cells lost their pseudopodia and exhibited evident cell shrinking, intracytoplasmic vacuoles, chromatin condensation and mitochondria swelling (magnification, x 5,000 ). CuB, cucurbitacin B.

examined by rhodamine 123 staining and flow cytometric analysis. The integral under the $\Delta \psi \mathrm{m}$ curve decreased and shifted toward the left; therefore, the proportion of depolarized cells increased in a dose-dependent manner following $\mathrm{CuB}$ treatment
(Fig. 8). The results indicated that cucurbitacin B treatment induced significant disruption of the $\Delta \psi \mathrm{m}$. As cytochrome $c$ release may be a limiting factor in caspase- 9 activation and represents a control coordinating step in apoptosis, the ability 


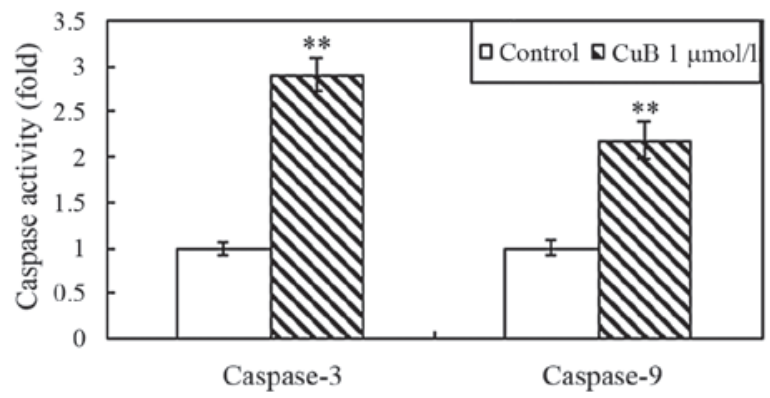

Figure 7. Effect of $\mathrm{CuB}$ on the activity of caspase-3 and -9 in CuB-induced apoptosis. A549 cells were treated with $\mathrm{CuB}(1.0 \mu \mathrm{mol} / \mathrm{l})$ for $24 \mathrm{~h}$. ** $\mathrm{P}<0.01 \mathrm{vs}$. the control group. $\mathrm{CuB}$, cucurbitacin $\mathrm{B}$; PI, propium iodide.

A

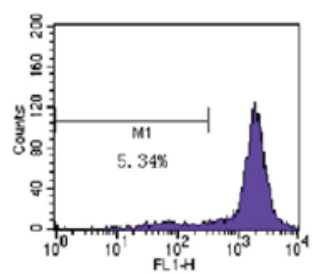

0

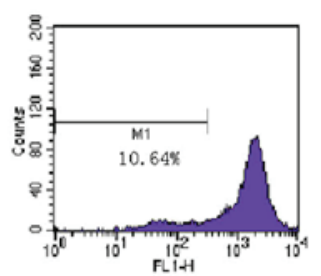

0.1

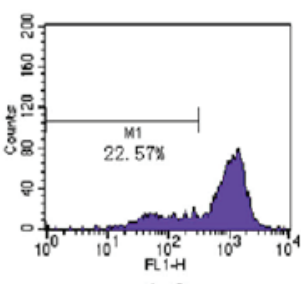

1.0

B

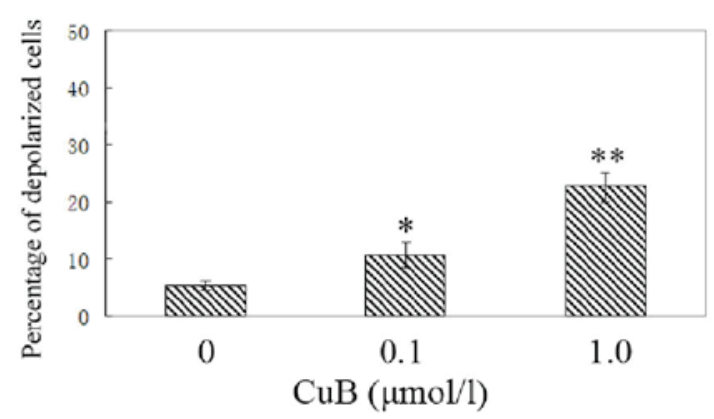

Figure 8. CuB induces disruption of $\Delta \Psi \mathrm{m}$. (A) A549 cells were treated with $\mathrm{CuB}(0,0.1$ and $1.0 \mu \mathrm{mol} / \mathrm{l})$ for $24 \mathrm{~h}$. The cells were then harvested, stained with rhodamine 123 and flow cytometric analysis was performed to analyze $\Delta \Psi \mathrm{m}$. (B) Quantification of the depolarization data from the histograms in $\mathrm{A}$. ${ }^{*} \mathrm{P}<0.05$ vs. the control group; ${ }^{* *} \mathrm{P}<0.01$ vs. the control group. $\mathrm{CuB}$, cucurbitacin $\mathrm{B} ; \Delta \Psi \mathrm{m}$, mitochondrial membrane potential.

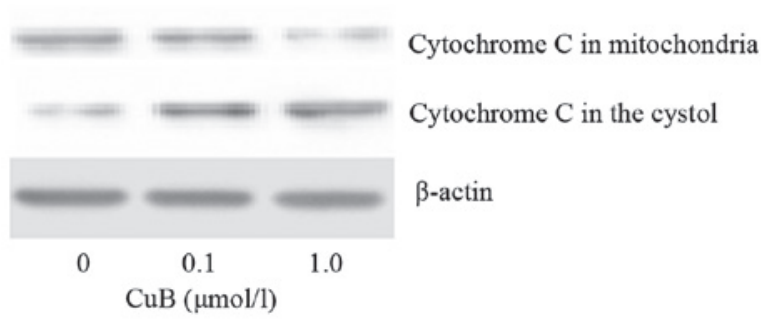

Figure 9. CuB induces the release of mitochondrial cytochrome C. A549 cells were treated with $\mathrm{CuB}(0,0.1$ and $1.0 \mu \mathrm{mol} / 1)$ for $24 \mathrm{~h}$. Following isolation of the mitochondrial and cytosolic fractions, mitochondrial cytochrome $\mathrm{C}$ release was detected by western blot analysis. $\mathrm{CuB}$, cucurbitacin $\mathrm{B}$.

of $\mathrm{CuB}$ to trigger cytochrome $c$ release was examined in A549 cells. As demonstrated in Fig. 9, CuB treatment induced the release of mitochondrial cytochrome $c$ into the cytosol.

$C u B$ downregulates the protein expression of phosphorylated (p)-STAT3, cyclinB1 and Bcl-2. To further examine the mechanisms of the effect of $\mathrm{CuB}$ on proliferation and apoptosis in A549 cells, a panel of proteins which are closely associated with cell growth and apoptosis were detected. CuB suppressed

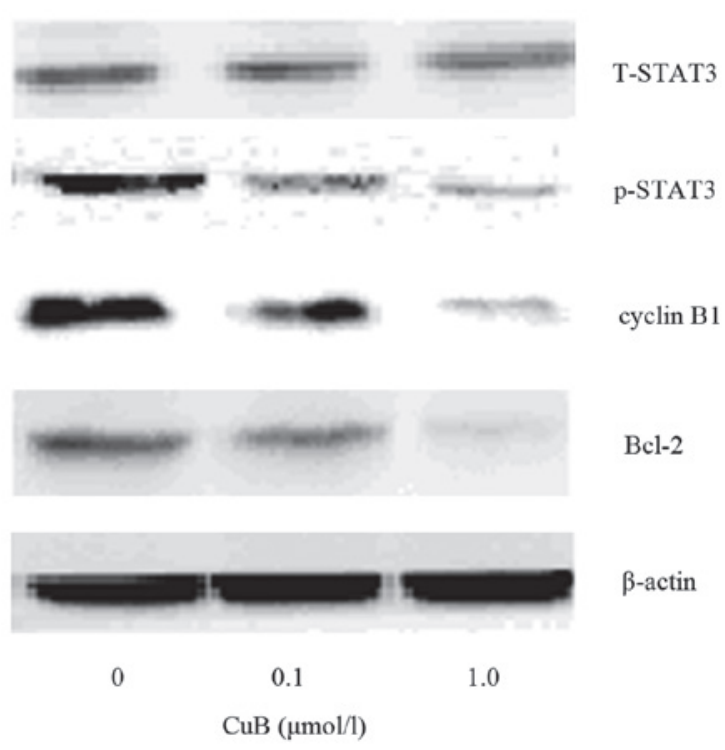

Figure 10. Effect of $\mathrm{CuB}$ on the expression of cyclin B1, p-STAT3, T-STAT3 and Bcl- 2 by western blot analysis. A549 cells were treated with $\mathrm{CuB}(0$, 0.1 and $1.0 \mu \mathrm{mol} / \mathrm{l})$ for $24 \mathrm{~h}$. The proteins were extracted, then cyclin B1, p-STAT3, T-STAT3, Bcl-2 and $\beta$-actin expression were analyzed by western blot. CuB, cucurbitacin B; P/T-STAT3, phosphorylated/total signal transducer and activator of transcription 3; Bcl-2, B-cell lymphoma 2. 
p-STAT3 in a dose-dependent manner, while it had no effect on the levels of total STAT3. Furthermore, it was identified that $\mathrm{CuB}$ treatment decreased the protein levels of cyclinB1 and Bcl-2 as well, which are downstream targets of STAT3 and are associated with cell growth and apoptosis. The results indicated that $\mathrm{CuB}$ affects proliferation and apoptosis through inhibiting STAT3 activation and subsequently decreased the levels of cyclin B1 and Bcl-2 protein expression (Fig. 10).

\section{Discussion}

Cucurbitacin B is a compound originally isolated from Cucurbitaceae plants and has hepatoprotective biological properties. Accumulating evidence has indicated that $\mathrm{CuB}$ inhibits proliferation and induces apoptosis in several human cancer cell lines (5,11-13). In the present study, it was identified that $\mathrm{CuB}$ may induce apoptosis in the lung cancer cell line A549. In addition, $\mathrm{CuB}$ inhibited the proliferation rate of A549 cells in a dose- and time-dependent manner. Further study revealed that $\mathrm{CuB}$ treatment caused $\mathrm{G} 2 / \mathrm{M}$ cell cycle arrest, elevated caspase- 3 and caspase- 9 activity, $\Delta \Psi \mathrm{m}$ disruption and cytochrome $c$ release. Examination of potential target protein expression revealed that $\mathrm{CuB}$ inhibited STAT3 phosphorylation, and downregulated cyclin B1 and Bcl-2 expression.

The induction of cell cycle arrest and apoptosis are common mechanisms proposed for the cytotoxic effects of anticancer drugs extracted from medicinal plants (14). In the present study the potential mechanism by which $\mathrm{CuB}$ inhibits cell proliferation was examined. Flow cytometry results demonstrated that $\mathrm{CuB}$ arrested cell cycle progression at the G2/M check point with a decreased G0/G1 ratio, thus inhibiting the cell proliferation rate. Accordingly, the expression of cyclin B1 was also decreased. Cyclin B1 is a regulatory protein involved in mitosis and may form a complex with cyclin-dependent kinase 1 (cdk1) (15). Cyclin B1-Cdk1 is involved in the early events of mitosis, including chromosome condensation, nuclear envelope breakdown and spindle pole assembly. Previous reports demonstrated that $\mathrm{CuB}$ was able to inhibit G2/M transition in breast cancer cells, laryngeal cancer cells and colon adenocarcinoma cells, which was in accordance with the results of the present study $(12,16,17)$.

$\mathrm{CuB}$ was reported to induce apoptosis in various cancer cell lines, including laryngeal, pancreatic, colon and hepatocellular carcinoma $(5,11,13,16)$. Using flow cytometry, fluorescence microscopy and transmission electron microscopy, it was demonstrated that $\mathrm{CuB}$ treatment induced lung cancer cell apoptosis in a dose-dependent manner. Mitochondrial dysfunction has been demonstrated to participate in the induction of apoptosis and has been suggested to be central to the apoptotic pathway. Further analysis of mitochondrial function revealed a disruption of $\Delta \Psi \mathrm{m}$ and cytochrome $c$ release. In addition, the levels of caspase-3 and caspase- 9 activity were also upregulated, coupled with downregulation of the anti-apoptotic Bcl-2 protein. The Bcl-2 protein regulates apoptosis by controlling mitochondrial permeability (18). Bcl-2 resides in the outer mitochondrial wall and inhibits cytochrome $c$ release (19). Upon release from the mitochondria, cytochrome $c$ binds to apoptotic protease activating factor 1 and forms an activation complex with caspase-9 $(20,21)$. Caspase- 9 activates caspase- 3 by proteolytic cleavage and caspase- 3 then cleaves vital cellular proteins or other caspases (22). Based on the present results, $\mathrm{CuB}$ may activate the apoptosis cascade through initiating cytochrome $c$ release and downregulating Bcl-2 protein expression.

Previous studies demonstrated that $\mathrm{CuB}$ suppressed the activation of STAT3, regulated STAT3 downstream genes and consequently inhibited tumor growth in several types of cancer $(11,13)$. Accordingly, a decrease of STAT3 phosphorylation following $\mathrm{CuB}$ treatment was identified. The STAT family proteins have been demonstrated to have important roles in tumorigenesis (23-25). Recent in vitro and in vivo studies have revealed that several strategies to target STAT3 signaling have been proposed as cancer therapies $(26,27)$. In addition, $\mathrm{Bcl}-2$ was a downstream target gene of STAT3 signaling. The results indicated that $\mathrm{CuB}$ may downregulate $\mathrm{Bcl}-2$ and induce apoptosis through inhibition of the STAT3 pathway.

In conclusion, the present study revealed that $\mathrm{CuB}$ inhibited proliferation in lung cancer cells, with cell cycle inhibition and cyclin $\mathrm{B} 1$ downregulation. $\mathrm{CuB}$ also induced lung cancer cell apoptosis through cytochrome $c$ release, $\mathrm{Bcl}-2$ downregulation and STAT3 pathway inhibition. CuB may serve as a potentially useful therapeutic strategy for patients with lung cancer.

\section{Acknowledgements}

The study was supported by Outstanding Scientific Fund of Shengjing Hospital (grant no. 201205).

\section{References}

1. Jemal A, Bray F, Center MM, et al: Global cancer statistics. CA Cancer J Clin 61: 69-90, 2011.

2. Schiller JH, Harrington D, Belani CP, et al: Comparison of four chemotherapy regimens for advanced non-small-cell lung cancer. N Engl J Med 346: 92-98, 2002.

3. Zhang Y, Zhang GB, Xu XM, et al: Suppression of growth of A549 lung cancer cells by waltonitone and its mechanisms of action. Oncol Rep 28: 1029-1035, 2012.

4. Reyes-Zurita FJ, Rufino-Palomares EE, Lupiañez JA and Cascante M: Maslinic acid, a natural triterpene from Olea europaea L., induces apoptosis in HT29 human colon-cancer cells via the mitochondrial apoptotic pathway. Cancer Lett 273: 44-54, 2009.

5. Liu T, Zhang M, Zhang $\mathrm{H}$, et al: Combined antitumor activity of cucurbitacin B and docetaxel in laryngeal cancer. Eur J Pharmacol 587: 78-84, 2008.

6. Jayaprakasam B, Seeram NP and Nair MG: Anticancer and antiinflammatory activities of cucurbitacins from Cucurbita andreana. Cancer Lett 189: 11-16, 2003.

7. Kongtun S, Jiratchariyakul W,Kummalue T, et al: Cytotoxic properties of root extract and fruit juice of Trichosanthes cucumerina. Planta Med 75: 839-842, 2009.

8. Zhang M, Zhang H, Sun C, et al: Targeted constitutive activation of signal transducer and activator of transcription 3 in human hepatocellular carcinoma cells by cucurbitacin B. Cancer Chemother Pharmacol 63: 635-642, 2009.

9. Hsu HF, Houng JY, Kuo CF, Tsao N and Wu YC: Glossogin, a novel phenylpropanoid from Glossogyne tenuifolia, induced apoptosis in A549 lung cancer cells. Food Chem Toxicol 46: 3785-3791, 2008.

10. Magesh V, Lee JC, Ahn KS, et al: Ocimum sanctum induces apoptosis in A549 lung cancer cells and suppresses the in vivo growth of Lewis lung carcinoma cells. Phytother Res 23: 1385-1391, 2009.

11. Thoennissen NH, Iwanski GB, Doan NB, et al: Cucurbitacin B induces apoptosis by inhibition of the JAK/STAT pathway and potentiates antiproliferative effects of gemcitabine on pancreatic cancer cells. Cancer Res 69: 5876-5884, 2009.

12. Liu T, Zhang M, Zhang H, Sun C and Deng Y: Inhibitory effects of cucurbitacin B on laryngeal squamous cell carcinoma. Eur Arch Otorhinolaryngol 265: 1225-1232, 2008. 
13. Chan KT, Meng FY, Li Q, et al: Cucurbitacin B induces apoptosis and $\mathrm{S}$ phase cell cycle arrest in BEL-7402 human hepatocellular carcinoma cells and is effective via oral administration. Cancer Lett 294: 118-124, 2010.

14. Xu X, Zhang Y, Qu D, Jiang T and Li S: Osthole induces G2/M arrest and apoptosis in lung cancer A549 cells by modulating PI3K/Akt pathway. J Exp Clin Cancer Res 30: 33, 2011

15. Jackman M, Lindon C, Nigg EA and Pines J: Active cyclin B1-Cdk1 first appears on centrosomes in prophase. Nat Cell Biol 5: 143-148, 2003.

16. Yasuda S, Yogosawa S, Izutani Y, et al: Cucurbitacin B induces $\mathrm{G} 2$ arrest and apoptosis via a reactive oxygen species-dependent mechanism in human colon adenocarcinoma SW480 cells. Mol Nutr Food Res 54: 559-565, 2010.

17. Yang L, Wu S, Zhang $Q$, Liu $F$ and $W u$ 23,24-Dihydrocucurbitacin B induces G2/M cell-cycle arrest and mitochondria-dependent apoptosis in human breast cancer cells (Bcap37). Cancer Lett 256: 267-278, 2007.

18. Braun F, de Carne Trecesson S, Bertin-Ciftci J and Juin P: Protect and serve: Bcl-2 proteins as guardians and rulers of cancer cell survival. Cell Cycle 12: 2937-2947, 2013.

19. Yang J, Liu X, Bhalla K, et al: Prevention of apoptosis by Bcl-2: release of cytochrome $\mathrm{C}$ from mitochondria blocked. Science 275: 1129-1132, 1997.

20. Hu Y, Benedict MA, Ding L and Nuñez G: Role of cytochrome $\mathrm{C}$ and dATP/ATP hydrolysis in Apaf-1-mediated caspase-9 activation and apoptosis. EMBO J 18: 3586-3595, 1999.
21. Malladi S, Challa-Malladi M, Fearnhead HO and Bratton SB: The Apaf-1"procaspase-9 apoptosome complex functions as a proteolytic-based molecular timer. EMBO J 28: 1916-1925, 2009.

22. Inoue S, Browne G, Melino G and Cohen GM: Ordering of caspases in cells undergoing apoptosis by the intrinsic pathway. Cell Death Differ 16: 1053-1061, 2009.

23. Niu G, Wright KL, Huang M, et al: Constitutive Stat3 activity upregulates VEGF expression and tumor angiogenesis. Oncogene 21: 2000-2008, 2002.

24. Diaz N, Minton S, Cox C, et al: Activation of stat3 in primary tumors from high-risk breast cancer patients is associated with elevated levels of activated SRC and survivin expression. Clin Cancer Res 12: 20-28, 2006.

25. Yeh HH, Chang WT, Lu KC, et al: Upregulation of tissue factor by activated Stat 3 contributes to malignant pleural effusion generation via enhancing tumor metastasis and vascular permeability in lung adenocarcinoma. PLoS One 8: e75287, 2013.

26. Chan KS, Sano S, Kiguchi K, et al: Disruption of Stat3 reveals a critical role in both the initiation and the promotion stages of epithelial carcinogenesis. J Clin Invest 114: 720-728, 2004.

27. Yu H and Jove R: The STATs of cancer - new molecular targets come of age. Nat Rev Cancer 4: 97-105, 2004. 